
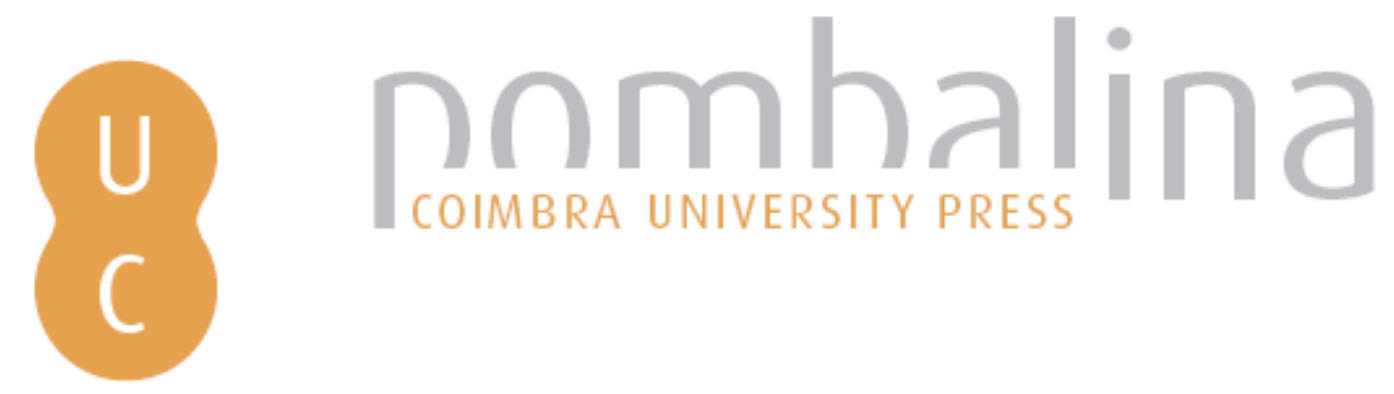

\title{
O Kochkäse e suas controvérsias como produtor de identidade, saúde e renda entre agricultores familiares do Vale do Itajaí (SC)
}

Autor(es): $\quad$ Silva, Marilda Checcucci Gonçalves da

Publicado por: Imprensa da Universidade de Coimbra; Annablume

URL

persistente: URI:http://hdl.handle.net/10316.2/39612

DOI: $\quad$ DOI:https://doi.org/10.14195/978-989-26-1191-4_3

Accessed : $\quad$ 26-Apr-2023 14:35:08

A navegação consulta e descarregamento dos títulos inseridos nas Bibliotecas Digitais UC Digitalis, UC Pombalina e UC Impactum, pressupõem a aceitação plena e sem reservas dos Termos e Condições de Uso destas Bibliotecas Digitais, disponíveis em https://digitalis.uc.pt/pt-pt/termos.

Conforme exposto nos referidos Termos e Condições de Uso, o descarregamento de títulos de acesso restrito requer uma licença válida de autorização devendo o utilizador aceder ao(s) documento(s) a partir de um endereço de IP da instituição detentora da supramencionada licença.

Ao utilizador é apenas permitido o descarregamento para uso pessoal, pelo que o emprego do(s) título(s) descarregado(s) para outro fim, designadamente comercial, carece de autorização do respetivo autor ou editor da obra.

Na medida em que todas as obras da UC Digitalis se encontram protegidas pelo Código do Direito de Autor e Direitos Conexos e demais legislação aplicável, toda a cópia, parcial ou total, deste documento, nos casos em que é legalmente admitida, deverá conter ou fazer-se acompanhar por este aviso.

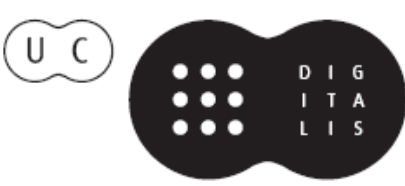




\title{
O KOCHKÄSE E SUAS CONTROVÉRSIAS COMO PRODUTOR DE IDENTIDADE, SAÚDE E RENDA ENTRE AGRICULTORES FAMiliares do VAle do Itajaí (SC) The Kochkäse and their disputes as a producer of identity, health and income among farmers of Vale do Itajai (SC)
}

\author{
Marilda Checcucci Gonçalves da Silva \\ Universidade Regional de Blumenau \\ Dept $^{\circ}$ de Ciencias Sociais e Filosofia \\ PPGDR em Desenvolvimento Regional da FURB
}

Resumo: O artigo resulta de pesquisa que teve como objetivo o Inventário do Kochkäse, enquanto um Patrimônio Cultural Imaterial do Vale do Itajá́, com base na metodologia do INRC do IPHAN. Agricultores familiares provenientes da Pomerânia, Mecklemburgo e Schleswig-Holstein que no ano de 1850, ocuparam a região do Médio Vale do Itajaí (SC) como colonos e seus descendentes, vêm tradicionalmente produzindo e consumindo o Kochkäse, queijo de origem alemã. Uma característica marcante do Vale do Itajaí ainda hoje é a presença de pequenas agroindústrias familiares que comercializam os produtos "típicos" da região provenientes dos saberes femininos. O Kochkäse, entretanto, enfrenta problemas com a vigilância sanitária que tomando como parâmetro legislação voltada para a lógica da grande indústria, não aprova sua comercialização por ele ser produzido com leite cru, o que acaba por obrigar o produtor a comercializar seu queijo na ilegalidade. Os resultados da pesquisa evidenciaram a importância do Kochkäse para a identidade e subsistência do grupo. Palavras-chave: Agricultores familiares de origem alemã; Kochkâse; Inventário; Vale do Itajaí; Santa Catarina; Brasil.

Авstract: The article derives from research that focuses on the Kochkäse Inventory as an Intangible Cultural Heritage of Vale do Itajaí, based on INRC methodology IPHAN. Family farmers from Pomerania, Mecklenburg and Schleswig-Holstein, who occupied the region of the Middle Itajaí Valley (SC) in 1850 as settlers, have been traditionally producing and consuming Kochkâse, cheese of German origin. A striking feature of the Itajai Valley is the presence of small family farms who sell the "typical" regional products from the female knowledge. The Kochkäse, however, faces problems with health surveillance which, taking as a parameter legislation facing the logic of the big industry, does not approve of their marketing because it is made with raw milk, which ultimately forces the artisan producer to sell its cheese illegally. The research results evidenced the importance of Kochkäse for group identity and survival.

KeYwORDs: Family farmers of German origin; Kochkâse; Inventory; Itajaí Valley; Santa Catarina; Brazil. 


\section{INTRODUÇÃo}

O presente artigo analisa e sistematiza informações sobre o Inventário do Kochkäse, queijo que vem sendo tradicionalmente produzido e consumido pela população de origem alemã, residente em vários dos municípios do Médio Vale do Itajaí. A pesquisa teve como objetivo o registro do queijo como patrimônio cultural imaterial do Vale do Itajaí/SC e a criação de um protocolo que permitisse e a sua comercialização mantendo as características tradicionais do produto que é feito com leite cru, já que existe uma exigência da Agencia Nacional de Vigilância Sanitária - ANVISA - para que ele seja feito com leite pasteurizado. Ocorre que a sua pasteurização altera o paladar do leite, o que não agrada ao produtor e consumidor da região, que há muitos anos o consome dessa maneira, o que leva à sua produção de forma ilegal. Esperou-se com o Inventário, oferecer condições para a manutenção de uma tradição que vem sendo passada de uma geração a outra, em especial graças ao saber-fazer das mulheres e que faz parte da memória coletiva e da identidade cultural compartilhada pelo grupo, garantindo um retorno econômico para essas famílias e promovendo-se um desenvolvimento regional sustentável.

A realização do projeto contou com uma equipe interdisciplinar, composta de dois subgrupos. Um deles responsável pelo Inventário histórico-antropológico do Kochkäse, coordenado pela autora do artigo e outro formado por um médico veterinário, um técnico na área da microbiologia e uma engenheira sanitária. O projeto contou ainda com a participação de alunos bolsistas da graduação e do mestrado. No artigo se fará referência mais diretamente à parte mais específica do Inventário histórico-antropológico. Os dados parciais que serviram de subsídio fazem parte dos resultados do Inventário realizado junto a famílias produtoras, dos municípios de Blumenau, Indaial, Pomerode, Benedito Novo, Timbó localizados no Vale do Itajaí (SC).

\section{OS IMIGRANTES E A OCUPAÇÃo DO TERRITÓRIO NO CENÁRIO REGIONAL}

O povoamento do Médio Vale do Itajaí iniciou-se com a fundação da Colônia Blumenau, sob a responsabilidade do alemão Hermann Bruno Otto Blumenau, químico-farmacêutico e filósofo, que com mais 17 imigrantes chegou às margens do Rio Itajaí-Açu, na foz do Ribeirão da Velha, em 02 de setembro de 1850. A princípio, a Colônia manteve-se como propriedade particular do fundador. Devido aos problemas financeiros pelos quais passava, em 1860, o Governo Imperial encampou o empreendimento. O Dr. Blumenau foi conservado na direção da Colônia e nela se manteve até quando esta foi elevada à categoria de Município, em 1880. Em 1886, o Município foi 
elevado a Comarca e em 1928, sua sede passou à categoria de cidade. Em 1934, começaram os desmembramentos do território municipal, sendo criados sucessivamente novos municípios no total de trinta. O desdobramento da Colônia Blumenau ao longo do tempo vai dar origem aos municípios que formam o atual Médio Vale do Itajaí, onde reside hoje a maioria de seus descendentes, que preservam muito das suas tradições e costumes, incluindo a língua.

A Colônia Blumenau foi povoada com imigrantes de origem alemã, vindo muitos agricultores da província de Pomerânia, Mecklemburgo e Schleswig-Holstein ${ }^{1}$. Italianos da região do Trentino Alto-Adige, da Lombardia (bergamascos e mantuanos) e do Vêneto foram também introduzidos pelo Dr. Blumenau na periferia da Colônia. Imigrantes de outras procedências também ingressarão depois, como é o caso de poloneses.

Além do Dr. Blumenau e da elite pequeno burguesa, formada por profissionais liberais e intelectuais que o acompanham, a população europeia imigrada para a Colônia Blumenau era em sua maioria camponesa. Agricultores que vieram em busca de uma vida melhor, atraídos principalmente pela possibilidade de se tornarem donos de uma pequena propriedade rural. Isso porque a grande concentração de terra na França, na Inglaterra e na Alemanha, fazia com que a maior parte das propriedades rurais não passassem de "meros retalhos de terras". Na Inglaterra, em 1873, sete mil famílias monopolizavam $80 \%$ das terras. Na Alemanha, em 1907, havia 5,5 milhões de propriedades com 2,5 a 50 acres, e 280 mil unidades com mais de cinquenta acres. Cerca de oito mil famílias controlavam $15 \%$ de toda a superfície cultivada. $\mathrm{Na}$ Itália $60 \%$ da população ativa se localizava na agricultura porem $80 \%$ dela não possuía terra ${ }^{2}$. O sul do Brasil oferecia as condições mais vantajosas para esse tipo de emigrante, cuja maior aspiração ainda era representada pela posse da terra. De fato, mesmo que através da abertura de terras virgens, a região oferecia a possibilidade de ele tornar-se, em poucos anos, dono de um sítio de dimensões bem maiores, em média, do que ele tinha tido na sua pátria ${ }^{3}$.

Esses municípios ainda hoje guardam características culturais que os diferenciam de outras regiões do país, em especial no que diz respeito à alimentação. Com a vinda das famílias imigrantes, desenvolveu-se na região uma significativa cultura alimentar formada através de duas tradições trazidas e aqui recriadas, uma rural e outra urbano-citadina, que foram aqui adaptadas à realidade local pelas mulheres imigrantes, já que se tratava de um novo território e ambiente físico ${ }^{4}$ diferente do conhecido.

\footnotetext{
${ }^{1}$ Wahle 1950: 131.

${ }^{2}$ Mayer e Azevedo (apud Woortmann) 1995: 121.

${ }^{3}$ Trento 1989: 79-80.

${ }^{4}$ Silva 2007.
} 
Essa rica tradição alimentar atualizada e ressignificada em diferentes momentos forma o que na atualidade se denomina de patrimônio cultural imaterial ou intangível, termo constituído a partir de uma visão crítica à noção anterior de patrimônio cultural e artístico que não contemplava as obras e ofícios tidos como "menores" em oposição àquelas de caráter erudito. A atual noção de patrimônio, além de fazer passar a noção da esfera privada para a esfera pública, do econômico para o cultural, ampliou a noção de patrimônio do material para o imaterial, o das práticas cotidianas e populares, longe das prestigiosas obras de arte ditas maiores, que são a música, a pintura, a poesia, incluindo aí, as tradições culinárias e gastronômicas. Inclui-se nessa noção de patrimônio cultural, manifestações tais como interpretações musicais e cênicas, rituais religiosos, conhecimentos tradicionais, práticas terapêuticas, lúdicas, culinárias e gastronômicas. Com isso viabiliza-se a leitura dos diferentes grupos culturais, sobretudo aqueles cuja tradição é transmitida oralmente, que sejam mais próximas dos sentidos que esta produção tem para seus produtores e consumidores. ${ }^{5}$

A alimentação, quando constituída como uma cozinha organizada, torna-se símbolo de uma identidade, atribuída e reivindicada através da qual os homens podem se orientar e se distinguir. Mais do que hábitos e comportamentos alimentares, as cozinhas supõem formas de perceber e expressar um determinado "modo" ou "estilo" de vida que se quer particular a um determinado grupo, podendo estar associadas a um território ou região. Assim, o que é colocado no prato serve para nutrir o corpo, mas também sinaliza um pertencimento servindo como um código de reconhecimento social. ${ }^{6}$

No Brasil, com as novas configurações do campo do patrimônio, em especial após o Decreto no. 3.551, de 4 de agosto de 2000, que institui o Registro de Bens Culturais de Natureza imaterial, a cozinha, enquanto patrimônio cultural alimentar, trazendo em si maneiras de saber e fazer, de narrar e celebrar, tem adquirido uma nova visibilidade. O Decreto determina que o "Registro de Bens Culturais de Natureza imaterial" seja constituído em quatro livros: "I - Livro de registros de saberes; II - Livro de registro das celebrações; III - livro de registro das formas de expressão; IV - Livro de registro dos lugares". O registro seria uma forma de colocar sob os holofotes determinada manifestação ou prática cultural. Ele trata não apenas de um elemento em si, mas de toda a contextualização que envolve seu sentido para o grupo local e para a sociedade brasileira. O processo de registro é um processo de patrimonialização, importando escolher um elemento considerado relevante ou emblemático e, portanto, representativo de um grupo. Em geral,

\footnotetext{
${ }^{5}$ Fonseca 2003:72

${ }^{6}$ Maciel 2003: 94.
} 
esses elementos são buscados no passado do grupo, no modo de vida, que é definido como "tradição".

Uma característica marcante do Vale do Itajaí é o desenvolvimento e a presença ainda hoje de pequenas agroindústrias familiares que comercializam legalmente os produtos "típicos" da região provenientes dos saberes femininos relacionados à culinária tradicional trazida e adaptada para a região com as primeiras mulheres imigrantes. Entre os produtos comercializados encontram-se a famosa cuca (Kuchen), pães caseiros, biscoitos, geleias e doces, licores e o queijinho branco.

Esta não é a situação do Kochkäse. Esse tipo de produto vem sendo comercializado por alguns produtores de forma ilegal, devido a problemas que enfrenta com a Vigilância Sanitária. A base da produção dessa iguaria está no leite cru desnatado. $\mathrm{O}$ processo de produção envolve a ordenha, a desnatação do leite, a formação do queijinho branco através do processo de coagulação natural do leite, o queijinho branco é então triturado e salgado, passa por um período de repouso que varia conforme a temperatura ambiente, após este período ocorre o aquecimento do queijinho branco "maturado" e o cozimento para a formação do Kochkäse. Existe uma resistência dos Serviços de Inspeção em aprovar a comercialização do produto por ele ser produzido com leite cru e não haver legislação específica do Ministério da Agricultura estabelecendo diretivas para a produção e comercialização. Porém, os agricultores acreditam que ao pasteurizar o leite, a essência do processo e o gosto do produto são alterados, perdendo-se também as suas características de um queijo artesanal tradicional.

\section{O PATRiMônio ALIMENTAR DE ORIGEM ALEMÃ EM BLUMENAU}

Para se compreender como foi aqui atualizado e ressignificado o sistema alimentar que forma o patrimônio cultural de origem alemã na região de Blumenau, é necessário entender em que consiste o sistema agrícola acoplado ao sistema produtivo característico da pequena propriedade familiar que se desenvolveu na região de imigração com a instalação das famílias camponesas imigrantes. A colonização privilegiou a pequena propriedade agrícola trabalhada com mão-de-obra familiar, o que se traduziu no tamanho dos lotes concedidos a cada unidade familiar - cerca de 75 hectares (que, na segunda fase do processo, foi sendo paulatinamente reduzido até chegar aos 25 hectares). Ela visava instalar no país agricultores livres e europeus (portanto, brancos), em áreas não ocupadas pela grande propriedade num processo controlado pelo Estado, preferencialmente de origem rural. Os

\footnotetext{
${ }^{7}$ Maciel 1996: 95.
} 
colonos alemães foram estabelecidos em regiões de floresta subtropical, acompanhando as bacias hidrográficas na direção da Serra Geral. Superada a fase pioneira, houve a consolidação de um campesinato característico das regiões de colonização, cujo fundamento está na pequena propriedade familiar (o lote, também chamado de colônia). O lote colonial pode ser definido como uma unidade produtiva baseada na policultura e criação de animais (aves, suínos, gado leiteiro) associadas com a produção artesanal de derivados como banha, queijo, manteiga, charutos, compotas de frutas etc. - as tarefas realizadas pelos membros da família numa divisão de trabalho simples. ${ }^{8} \mathrm{~A}$ palavra colônia, tem duplo significado. Engloba a área colonizada como um todo (portanto, o meio rural) e, ao mesmo tempo, designa a unidade mínima de produção (o lote), cujos proprietários adotaram a designação oficial de colonos como indicativo da condição camponesa9 ${ }^{9}$. Esse complexo colonial, é estruturalmente camponês - a colônia no seu sentido representando uma combinação de economia doméstica e empresa, elementos básicos da definição econômica do campesinato ${ }^{10}$. A "sistemática de exploração agrícola, a formação de uma classe média rural de pequenos produtores e a diversificada atividade artesanal são apontadas por diversos autores como características do complexo colonial." ${ }^{11}$

Praticavam a cultura da subsistência, onde tudo o que precisavam era produzido na pequena propriedade, exceto o sal de cozinha, o querosene e o açúcar refinado e somente os excedentes eram comercializados. Além disso, a pequena indústria familiar, artesanal, proliferou nos povoados e cidades dentro de áreas colonizadas. Fábricas de conservas, laticínios, salsicharia e bebidas (incluindo cervejarias) curtumes, funilarias, ferrarias, sapatarias, destilarias, etc. operando com a mão-de-obra familiar e poucos empregados, foram comuns até a década de 1940. A família rural teuto-brasileira organizava-se como unidade produtora contando apenas com os seus membros para a realização dos trabalhos. Ela era estruturada no modelo da família camponesa da Alemanha do século XIX. O regime de trabalho adotado pelos colonos consistia na divisão das tarefas rurais entre os membros familiares. A derrubada da mata era executada pelos homens, bem como todo serviço pesado da lavoura e criação dos animais, este era auxiliado pela esposa que conciliava os serviços externos com os domésticos, do pomar, do jardim e a educação dos filhos. Após sete anos os filhos ajudavam os adultos na capina e colheita de roças, nos cuidados da horta e na forragem para os animais e frequentavam a escola.

\footnotetext{
${ }^{8}$ Seyferth 1999: 277-289.

${ }^{9}$ Seyferth 1993: 80.

${ }^{10}$ Seyferth (apud Galeski, Chayanov e Shanin) 1999: 289.

${ }^{11}$ Seyferth (apud Willems, Diegues, Roche) 1999: 290.
} 
A industrialização iniciou-se em diversos núcleos urbanos em fins do séc. XIX, impulsionada, em parte, pelo capital comercial - isto é, pela acumulação realizada por comerciantes teuto-brasileiros integrantes do sistema colônia/ venda. O progresso do comércio da produção rural, por sua vez, acumula capitais, que passam a ser investidos na experiência artesanal e fabril dos imigrantes alemães, criando-se a indústria têxtil da região, responsável por sua identidade econômica. $\mathrm{O}$ crescimento da indústria têxtil e metalúrgica no vale do Itajaí, além do crescimento de frigoríficos e outras fábricas de alimentos, abriram um mercado de trabalho para filhos de colonos, com a formação de uma classe operária, que mais tarde seria integrada por brasileiros, e de um segmento de "colonos-operários", famílias que permaneceram nas suas colônias, praticando agricultura em tempo parcial - worker peasent - identificados socialmente com o meio rural, apesar da condição operária de um ou mais de seus membros. No Vale do Itajaí estes constituem hoje uma parcela significativa da população. O processo de urbanização ocorreu de maneira simultânea ao desenvolvimento industrial, consolidando uma classe média urbana diversificada e numericamente expressiva e uma pequena elite de comerciantes e industriais, que tiveram papel importante na formulação da identidade teuto-brasileira ${ }^{12}$.

O caráter comunitário de muitas instituições se fez presente, em parte devido às carências vividas, mas também em consequência da recriação em território blumenauense de muitas das instituições já existentes na Alemanha. A criação da "escola alemã" e a implantação de serviços médicos, a organização do serviço religioso, inicialmente por pastores e padres leigos, foram algumas destas. Com o mesmo caráter comunitário, proliferaram nas colônias as associações beneficentes e assistenciais, para atendimento médico-hospitalar, socorro mútuo, orientação técnica para os colonos, etc. (com as denominações de Hilfsverein, Krankenverein, Kulturverein). A vida associativa, também formalizada por teuto-brasileiros aparece nas associações culturais, recreativas e esportivas, entre as quais se destacaram três tipos - Schütenverein (Sociedade de Atiradores), Turnverein (Sociedade de Ginástica) e Gesangrerein (Sociedade de Cantores), símbolo do estilo de vida germânico, expressando a Deutschum. As duas primeiras, tinham como atividade principal a prática esportiva do tiro, atletismo, ginástica e, mais tarde, esportes coletivos como vôlei e futebol, mas patrocinavam também representações teatrais, bailes, concertos e outras atividades culturais. A última visava a divulgação do Lied, canto coral e manifestações folclóricas ${ }^{13}$. O uso cotidiano da língua alemã, a intensidade da vida associativa, a rede

\footnotetext{
12 Seyferth 1999: 290-291.

13 Seyferth 1999: 292.
} 
escolar particular, a imprensa teuto-brasileira e outras publicações periódicas, inclusive a produção literária, pelas apregoadas vinculações com ideais de germanidade ajudaram a construir uma identidade teuto-brasileira. As distinções em relação à sociedade brasileira remetem ao contraste demarcado pelas singularidades sociais e culturais. Inclui a "família tronco" (três gerações que vivem sob o mesmo teto) ligada à propriedade e associada ao minorato, apontando para o sistema costumeiro de herança da terra que privilegia o herdeiro único (no caso, o ultimogênito). Hábitos alimentares produto da adequação brasileira à culinária germânica, a Wobnkultur, com seu ideário de conforto e "bem viver", a organização do espaço doméstico, os elementos de decoração das casas (como os panos de parede bordados com alegorias e ditados populares) ${ }^{14}$, (a participação das mulheres nas atividades esportivas e sociais desenvolvidas nas associações, o grande número de festas, inclusive os bailes realizados em numerosos salões, espalhados pelas linhas e nas cidades, são algumas das especificidades que apontam para um estilo de vida e um ethos do trabalho mais propriamente teuto-brasileiro, utilizados como marcadores identitários ${ }^{15}$.

Esses imigrantes quando recém-chegados encontraram uma agricultura local feita por brasileiros, denominados pelos colonos de "caboclos", à qual aderiram no período inicial, pois os produtos que eram produzidos na Alemanha aqui não se desenvolviam da mesma maneira, já que estes se encontravam em um novo território, cujas condições climáticas e geográficas eram muito diferentes das regiões de origem. Em consequência, vai haver um processo de alteração e mudança dos hábitos alimentares dos colonos e uma adaptação àquilo que podia ser cultivado no Brasil. O pão de trigo ou de centeio, a batata e os legumes diversos constituíam, na Europa, a base normal da alimentação do camponês. Nos primeiros anos após sua chegada à colônia Blumenau, as principais ocupações dos imigrantes se prenderam sempre ao cultivo daquilo que já conheciam em seus países e regiões de origem, entretanto, estas experiências não lhes trouxeram resultados satisfatórios. Em consequência passam a plantar os produtos nativos, cultivados pelo agricultor brasileiro.

Na colônia Blumenau, o trigo e o centeio não vingavam pois o clima não era propício, trocaram a farinha de trigo pelo fubá de milho branco, produzindo o famoso pão de milho, a batata pela batata doce, aipim e tubérculos locais, visto que seu rendimento era maior e não exigiam uma terra muito boa e fértil. Aos alimentos originais dos imigrantes, batata inglesa, carne de porco, legumes e trigo - aqui foram contrapostos o milho, o arroz, a mandioca, o

\footnotetext{
${ }^{14}$ Seyferth 1999: 297.

15 Seyferth 1999: 297.
} 
fubá, o cará, o feijão, e a carne de gado. ${ }^{16} \mathrm{O}$ milho serviu para a alimentação da família, para alimentar os animais e para o mercado, enquanto do leite a ordenha da manhã era reservada para a família e somente a restante era vendida aos laticínios, surgidos na região por iniciativa de imigrantes alemães. Usados para a subsistência da família, os animais cuidados eram algumas vacas, um máximo de quatro, alguns porcos, algumas galinhas e patos. Pelo menos uma vaca costumava ser trazida pela esposa, por ocasião do casamento e formação do grupo doméstico, ocasião em que a filha a recebia como parte do dote do pai, ou herança. Muitas famílias possuíam uma ou mais vacas para produção do leite, do qual faziam a manteiga, a ricota, a nata e o queijo. A suinocultura é muito difundida em todo o Sul desde o século passado, atividade também trazidas por colonos alemães. A razão para sua criação estava colocada para além do interesse comercial mais imediato, já que esses animais eram alimentados por tubérculos, raízes e legumes excedentes do consumo doméstico que não compensava vender, fornecendo por outro lado carnes e derivados que constituíam parte importante da dieta do colono. A carne de boi era menos consumida, pois precisava ser comprada nos açougues que funcionam nos povoados ou nas cidades. $\mathrm{O}$ abate dos porcos se fazia em mutirão e acabava no final em festa onde se comiam linguiças, morcelas, banha, além da própria carne, defumada ou não, que constituíam, juntamente com as aves (galinhas, patos, marrecos), o suprimento de proteína animal. ${ }^{17}$ A subsistência desses camponeses/colonos dependia de três produtos nativos básicos: o milho, o aipim e a cana-de-açúcar.

\section{A cultura alimentar dos imigrantes e seus descendentes}

Para se compreender como foi aqui atualizado e ressignificado o sistema alimentar que forma o patrimônio cultural de origem alemã na região de Blumenau, é necessário entender em que consiste o "sistema agrícola" acoplado ao sistema produtivo característico da pequena propriedade familiar que se desenvolveu na região de imigração com a instalação das famílias imigrantes na condição de colonas que por sua vez irá resultar em um "sistema alimentar" através das transformações operadas nos produtos daí derivados pelas mulheres colonas.

Esse "sistema" pode ser pensado como constituído por uma lógica própria que organiza as combinações de espécies e variedades vegetais, formando ecossistemas construídos com base em modelos de saber e de conhecimento da natureza que fundamenta a prática da lavoura..$^{18}$ Acrescento a esse modelo a

\footnotetext{
${ }^{16}$ Silva 2007: 118.

${ }^{17}$ Seyferth 1999: 34

${ }^{18}$ Woortmann e Woortmann 1997: 7.
} 
inclusão de variedades de animais, que obedece também a uma combinação e lógica próprias, integrada ao conhecimento das espécies e variedades de plantas e ao meio-ambiente que constitui o microcosmo da propriedade familiar.

Esse saber é mais do que um conhecimento especializado, constituindo-se como parte de um modelo mais amplo de percepção da natureza e dos homens. $\mathrm{O}$ processo de trabalho faz-se a partir de uma idealização da natureza. $\mathrm{Ou}$ seja, não existe uma natureza em si, mas uma natureza cognitiva e simbolicamente aprendida. Ele se faz no interior de um processo de relações sociais que transforma a natureza. Para entendermos seu processo de construção precisamos conhecer tanto o modelo cultural, quanto o processo histórico da sociedade, pois não existe uma natureza independente dos homens. A natureza é transformada, inclusive pelo processo de trabalho.

O processo de trabalho dá-se pela articulação de forças produtivas com relações sociais de produção. A noção de forças produtivas, tal como utilizada pela sociologia, significa o conjunto de fatores de produção: recursos disponíveis, homens e instrumentos de trabalho. Contudo, nem os recursos nem os instrumentos e os homens existem socialmente sem a cultura. É o saber que permite usá-los e é a cultura que lhes dá significado, inclusive para mais além da materialidade ou da instrumentalidade prática do trabalho. Ainda que a noção de relações de produção seja vinculada à ideia de classes sociais, pode-se dar a ela um outro sentido voltado para as relações que se estabelecem no interior do grupo social específico que realiza a produção, sendo no caso do trabalho camponês, a unidade familiar. A partir de uma concepção marxista de trabalho, é possível refinar a noção de forças produtivas, percebendo-as como "os meios materiais e intelectuais que os membros de uma sociedade implementam, dentro dos diferentes processos de trabalho, a fim de trabalhar a natureza e extrair dela os seus meios de existência, transformando-a, assim, em natureza socializada" ${ }^{19}$ (grifos do autor).

Os meios intelectuais podem ser entendidos a partir dessa concepção como os modelos de saber pelos quais e através dos quais os homens agem sobre a natureza. Os meios materiais só existem socialmente a partir dos meios intelectuais, e é por meio destes que a natureza se torna socializada. Os meios intelectuais seriam o saber e este é um código linguístico reproduzível pela transmissão e pelo aprendizado. No caso do campesinato a transmissão desse saber para o trabalho faz-se no próprio trabalho - pois o saber é um saber fazer, parte da hierarquia familiar, subordinado ao chefe da família, via de regra o pai, que governa o trabalho como também o fazer-aprender. Exerce-se o poder porque se detém o saber. No caso do campesinato o pai de família (no plano público) governa a família porque governa a produção; governa o

\footnotetext{
${ }^{19}$ Woortmann e Woortmann (apud Godelier) 1997: 10-11.
} 
processo de trabalho porque "domina" o saber. ${ }^{20}$ Porém se o homem detém o saber da agricultura, a mulher detém o saber que lhes permite transformar os produtos da agricultura de alimento (natureza) em comida (cultura), através de um saber-fazer, passado de mãe a filha (ou a nora), a cada geração. Esse saber-fazer no caso da região estudada se encontra vinculado a um modo de vida, que caracteriza a maneira de viver das famílias dos pequenos agricultores, que os identifica e faz com que sejam identificados pelos outros como "colonos" e "colonas". Esse aspecto é importante pelo fato de que na maioria dos estudos sobre o campesinato, pouca atenção ou nenhuma vem sendo dada ao saber camponês sobre os solos e plantas, visto como sistema cognitivo, parte de um modelo mais abrangente. O estudo do saber como um sistema permite compreender o campesinato como produtor de categorias de apreensão do real e entender o processo de trabalho sobre novas perspectivas. ${ }^{21}$ Esse saber fazer feminino permitiu a recriação de um sistema culinário e uma cozinha que forma ainda hoje o patrimônio alimentar do grupo, ainda que mudanças estejam ocorrendo devido às transformações por que passa a área rural na região em consequência do processo de modernização agrícola. O Kochkäse é parte desse sistema.

\section{DE ALIMENTO À COMIDA: O PAPEL DA MULHER CAMPONESA IMIGRANTE NA ADAPTAÇÃo E TRANSFORMAÇÃo DOS PRODUTOS AGRÍCOLAS.}

O "sistema agrícola" acoplado ao sistema produtivo característico da pequena propriedade familiar que se desenvolveu na região de colonização do Vale do Itajaí com a instalação das famílias camponesas imigrantes - mediado pelo habitus ${ }^{22}$ internalizado pelas mulheres - irá resultar em um "sistema alimentar" através das transformações operadas nos produtos daí derivados. No caso da família camponesa imigrante que se dirigiu ao Vale do Itajaí, a mulher foi a responsável por adequar os produtos da agricultura local à culinária alemã, que irá se atualizar aqui com base em um habitus de origem trazido e modificado em função do novo contexto agrícola. Assim, se num primeiro momento serão em especial os homens que irão adequar o sistema agrícola ao contexto local, dado que quem dá a "direção" na propriedade é o pai de família, e que a roça é um espaço masculino, em um segundo são as mulheres que irão adequar sua culinária a esse sistema agrícola aqui adaptado. Elas irão operar substituições em suas receitas. Desse modo irão substituir a maçã pela banana, laranja, frutas encontradas aqui, ou incorporaram novos

\footnotetext{
${ }^{20}$ Woortmann e Woortmann 1997:11.

${ }^{21}$ Woortmann e Woortmann 1997:14.

${ }^{22}$ Bourdieu 1989: 61
} 
modos de fazer, como a rosca e os biscoitos a partir do polvilho, produto extraído da mandioca, que antes lhes era desconhecida.

No trabalho realizado em campo para o Inventário do Kochkäse, identificamos na culinária dos colonos a presença de geleias, feitas com açúcar e frutas da estação, como figos, laranjas, maçãs, peras, etc. provenientes dos pomares, a Muss, feita com as mesmas frutas, porém cozidas com o melado produzido em tempos antigos nos engenhos de cana, hoje industrializados, que era comido schimeado em cima do pão. De acordo com Dona Ingrid (agricultora) schmia é tudo aquilo que se passa em cima do pão.

A cuca ou Kuchen é também bastante consumida em especial no domingo e dias festivos. Trata-se de uma massa de um tipo de mistura de bolo e pão, ao qual se agrega diferentes coberturas. São muito apreciadas as cucas de queijo, banana, nata com canela. Em tempos antigos elas eram feitas com fermento, que nem sempre se utiliza hoje. Uma das mais apreciadas é a Streuselkuchen onde vai uma cobertura de açúcar, gordura (manteiga ou margarina) e farinha de trigo, formando pequenos grumos em cima da base.

O pão é um alimento bastante presente no cotidiano, sendo feito ainda hoje por muitas agricultoras. Faz parte do café da manhã e da noite. Em tempos antigos era feito com o milho, já que durante muito tempo a farinha de trigo era um objeto de luxo. Era comum também se fazer o pão com cará e batata-doce ralados, ao qual se acrescentava o fermento, sendo assado na folha de bananeira no fogão a lenha encontrado do lado de fora da casa e ainda hoje utilizado nas propriedades rurais pesquisadas. A farinha de milho ou fubá era levada para moer nas atafonas existentes na região, à qual nem todos os colonos tinham acesso. Isso era feito uma vez por mês. Ela era guardada em caixas de madeira próprias para isso ou em sacos bem amarrados dentro dos armários.

Os derivados do porco eram também muito consumidos. De acordo com Roseli Grossglags (agricultora), do porco se comia tudo, a banha, os pés, o rabo, as orelhas, bem como o toucinho, que era salgado e se colocava no feijão, que não se costuma comer todos os dias, mas uma vez por semana e na forma de feijoada, com carne, linguiça, etc. A banha era comum que se comesse com açúcar em cima do pão. Também se fazia uma geleia de porco, denominada Sülze. Se preparava ainda com o torresmo uma pasta para comer com o pão que segundo ela seus pais apreciavam muito. $O$ torresmo era moído na máquina de moer carne e temperado com sal e cebolinha verde. Sua sogra fazia a morcela branca, feita com a carne, língua, algumas vezes pedaços de fígado, cozidos e temperados e a preta à qual se acrescenta às mesmas carnes o sangue do porco e temperos. Algumas partes do porco eram feitas defumadas, costume que ela mantém até hoje. Com os ossos da costela do porco que sobravam, torrava-se, cortava-se bem pequeninho e colocava-se no feijão. 
Finalmente são também muito consumidos pelos colonos os produtos derivados do leite, como a manteiga, a nata e a ricota feita com o leite dessorado, bem como o queijo. São consumidos ainda hoje dois tipos de queijo. $\mathrm{O}$ "queijinho branco" ou Weisserkäse, feito a partir do leite dessorado e deixado maturar também chamado de Kremmerkäse e o Kochkäse - objeto de Inventário - feito a partir do "queijinho branco" maturado colocado para cozinhar na temperatura de 70 graus. Um outro tipo de queijo denominado "queijinho de mão" ou Handkäse, que é produzido a partir do "queijinho branco" com sal, no formato de bolinhas e secado na janela da cozinha, atualmente está desaparecendo, sendo feito por poucas agricultoras que ainda conservam o seu modo de fazer. Era também feito um queijo especial com o colostro.

O Kochkäse também chamado de Stinkase (queijo fedido) ou Stinky (cheiro forte), assim como tudo que diz respeito à culinária é feito tradicionalmente pelas mulheres, sendo passado seu saber-fazer de uma geração a outra. As mulheres agricultoras relataram terem aprendido com suas mães que por sua vez aprenderam com suas avós e estas com as suas bisavós. Na primeira e segunda geração das avós e bisavós, ele era feito somente para a família. Com o aumento da bacia leiteira, ele passou a ser comercializado, sendo considerado hoje como o produto que oferece o maior retorno econômico para a família.

Como já falado ele vem sendo comercializado ilegalmente, devido à sua proibição pela ANVISA, que exige a sua adequação a regras impeditivas para os colonos do ponto de vista econômico ou porque se recusam a pasteurizar o leite pelo fato de considerarem que altera o paladar e faz com que se perca as características de um produto tradicional, para o qual existe demanda. Seu consumo sempre fez parte da comida cotidiana do colono, sendo muito apreciado e difundido na região. Ele é comido no pão no café da manhã, no früschten (refeição feita por volta das nove horas) e à noite, sendo acompanhado de geleias e Muss.

Além do seu consumo no cotidiano o Kochkäse juntamente com o Heringsbrot, - que consiste em pão recheado com uma mistura de ovo e sardinha ou arenque em salmoura - não pode faltar nas festas que fazem parte dos rituais cotidianos, tanto do ciclo doméstico familiar como litúrgico, sendo considerados o "carro-chefe". Estas festas, costumam ser realizadas em especial nos Salões, locais ainda hoje existentes nos Clubes de Caça e Tiro, nas igrejas, ou mesmo pertencentes a comerciantes.

Como pratos específicos da culinária em tempos antigos era feito o Sauerkraut, com repolho picado fino, salgado e fermentado, substituído mais recentemente pelo produto industrializado. O marreco recheado ou Gefullte ente, servido até hoje com aipim, arroz, e não com repolho roxo e purê de maçã, como é servido em restaurantes na área urbana e veiculado pela mídia. É feita ainda hoje a famosa Sopa Preta ou Schwartsauer durante a "Festa do Quebra Caco" ou Polterabend, que acontece na sexta-feira, dia que antecede o 
casamento e se começam os preparativos para o mesmo, com a matança das aves que serão recheadas e assadas no dia seguinte. Durante essa ocasião são entregues aos noivos cacos de louça velha quebrada enrolados em papel de presente, que é deixado cair na hora de se entregar. Os noivos devem juntar tudo e jogar fora. Além de servir como metáfora para a vida a dois, onde o casal que está enfrentando dificuldades, deve seguir o exemplo de "reunir sempre os cacos”, superando as situações difíceis que o casal deverá enfrentar na sua vida conjugal, acredita-se que catar os cacos traz sorte para os noivos. Roseli Grossglags (agricultora) contou que era comum também se fazer a sopa preta, com o sangue do porco, embora hoje esteja caindo em desuso. O sangue era aproveitado de diversas maneiras, uma delas eram os bolinhos temperados com cheiro verde e cebolinha comidos fritos. A Schwartsauer segundo Adalberto Lorenz (agricultor) costumava até recentemente ser servida nas festas da Igreja (tanto católica como protestante) que acontecem em função das comemorações dos Santos padroeiros das localidades, embora isso já não aconteça hoje por ter sido proibido pela Vigilância Sanitária.

\section{Mudanças Na Agricultura familiar dos colonos}

Os esforços empreendidos pela família dos agricultores na lavoura e na criação de animais foram compensados pelo crescimento agrícola, possibilitando o beneficiamento doméstico do leite, da manteiga, queijo e do porco em banha. A venda do porco em banha foi fundamental no primeiro momento da vida dos colonos principalmente porque não existia energia elétrica e o processo de conservação dos alimentos, em especial da carne de porco, se dava através da sua imersão na banha, que era guardada em latas ou defumada, costume trazido com os imigrantes. A carne de gado não se prestava a esse tipo de conservação, motivo pelo qual ela ocorria através da salga, sendo transformada em charque, como costuma ser feito entre agricultores brasileiros. Seu uso era restrito. Como uma forma de se consumir carne fresca, existia a prática de durante o abate do porco ou do gado, se distribuir parte da carne entre os vizinhos, que por sua vez retribuíam quando faziam o mesmo. $\mathrm{Na}$ atualidade com a presença da energia elétrica e do freezer já não se faz tanto isso e as relações de reciprocidade e solidariedade, ainda que existam, se modificaram bastante, não sendo tão frequentes como eram antigamente.

A criação de suínos para a venda da banha, foi realizada na sua forma tradicional até a década de 1970. Entretanto a expansão do mercado de óleos vegetais, principalmente com a expansão da soja, traria a desvalorização comercial da banha. Com isso, as antigas raças de suínos seriam substituídas pelo porco branco, em cuja produção é priorizada a carne. $\mathrm{O}$ porco comum, tipo banha, era criado solto, na mangueira, sendo tratado com mandioca, milho (também em espiga) e lavagem, feita à base de batata-doce, abóbora e 
restos de comida. Esse sistema de criação modificar-se-ia com as novas raças, que passariam a ser criadas em confinamento e à base de rações compradas. Antes, contam os agricultores entrevistados, o porco era preso para engordar depois do sexto mês, necessitando de mais seis meses para estar pronto para o abate. Hoje, no sistema de integração, é comercializado a partir de cinco meses de idade. ${ }^{23}$

De acordo com Roseli Grossglags, 48 anos, agricultora em tempo parcial e operária na Karsten, desde os 14 anos (local onde trabalhou toda sua família, incluindo seu pai, hoje aposentado e sua mãe que deixou de trabalhar com o nascimento dos filhos) seu estilo de vida é ainda hoje parecido com o da sua sogra que mora com ela e o marido - já que a residência no casamento condiciona a patrilocalidade do ultimogênito - sendo na sua visão, a diferença fundamental, o fato de ela e o marido trabalharem fora:

O nosso estilo de vida é mais ou menos parecido, é claro que a oma nunca trabalhou fora, isso é um grande diferencial assim. Eles trabalhavam na roça direto, era só na roça. Todo o sustento pra casa, pra criar os filhos, tirava-se da terra, era do leite, era das plantações, alguma coisa que conseguia vender, ou plantava pra criar animais, vender animais, ou principalmente pra consumo próprio. Antigamente não tinha essas leis ambientais rígidas como tem hoje em dia, acho que nem tinha. Daí meu sogro... porque tirava muita madeira... muita tora vendia pra serraria, aí vendia uma cabeça de gado, quando precisava de um pouquinho mais de dinheiro, tanto é que os quatro filhos botaram na escola, tiveram escolaridade também baixa, mas tiveram, e foi tudo sustentado pelo meu sogro e tudo tirado da roça. Da roça, do mato, das plantações, a principal atividade deles na época era o leite, porque eles tinham seis ou sete vacas de leite, não sei, ou tinha mais até?. A principal atividade era a venda do leite, aí quando precisava de um pouquinho mais de dinheiro, tirava toras, vendia a tora pra serraria...

A fala da Roseli Grossglags sobre a sua sogra, remete a um primeiro momento da vida dos colonos na região, quando o trabalho estava somente voltado para a subsistência da família e todos trabalhavam na lavoura. Nesse período o principal rendimento da família que forma o grupo doméstico era proveniente da venda do leite e o gado leiteiro era encontrado em todas as propriedades. $\mathrm{O}$ gado leiteiro assim como o bovino eram tratados com pasto e assim como as galinhas, alimentados com mandioca, batata-doce, bem como as sobras das comidas. No inverno se subia o morro e se colhia folhas de "caeté", que hoje em dia não se corta mais porque se tem a "silagem", que consiste no milho cortado com folhas e talos e estocado em toneis lacrados ou "silos". Hoje é também comum que se forneça ração, farelo de

\footnotetext{
${ }^{23}$ Menasche 2007: 86.
} 
trigo, farelo de algodão, arroz ou soja para o gado, além de capim elefante e gramon. Durante o inverno se planta consorciada com o milho a aveia, que também serve de alimento para o gado. O leite até algum tempo atrás era deixado pelo produtor na frente da sua casa em $b_{u l e s}{ }^{2}$, sendo pego todos os dias e transportado em carroças até o local de sua distribuição, as vendas, que redistribuíam aos inúmeros laticínios e queijarias da região. Como explica Roseli Grossglags:

É, e ali eles vendiam... vendiam esse leite e eles também... tinham um mercado... $\mathrm{E}$ as coisas que eles não produziam aqui na terra, na roça, eles pegavam, em vez do dinheiro todo do leite, eles pegavam parte... em gêneros alimentícios... era o sal que eles compravam, compravam as vezes açúcar, que geralmente era o açúcar mascavo, o trigo e macarrão, coisinhas assim que não tinham em casa... eles compravam nesse mercado... já aproveitava pra comprar no mercado... e o restante que seguia o valor é... eles ganhavam em dinheiro... era com isso que eles sobreviviam durante o mês.

Era uma vida de muita poupança e sacrifício, pois somente assim se conseguia estruturar de forma equilibrada a vida econômica na pequena propriedade familiar, em especial os colonos fracos que diferente do colono forte, não tinham condições de passar para os filhos o necessário ${ }^{24}$. Entretanto a maioria dos entrevistados foi unânime em afirmar que nessa época se vivia melhor, de uma maneira mais "natural", pois não se utilizavam agrotóxicos nos alimentos e nem se dava ração para os animais, o que permitia a produção de alimentos mais saudáveis e possibilitava que se tivesse uma saúde melhor, revelando um sentimento de nostalgia do passado.

Porque naquela época não era assim como hoje que tem uns gatos pingados com gado leiteiro, na época da oma, quando mais nova, todo mundo na região era só isso que tinha, daí não tinha como você vender uns dois ou três litros de leite pro vizinho, ou vender um quilo de manteiga, ou meio quilo de queijo. Hoje em dia, se eu tivesse mais tempo, mais vacas leiteiras, eu poderia vender aqui aos vizinhos: queijo, manteiga, leite, kochkäse. Tudo poderia vender, porque quase ninguém mais tem gado leiteiro. Essa é a diferença, antigamente não tinha como você vender perto, era aquele um comprador e deu, e era esse o sustento. Também não é quinem hoje que a gente vê uma bijouteria bonita na vitrine e "oh, essa eu vou comprar”, não tinha como comprar supérfluos, era o básico e pronto.

O esgotamento da terra associado ao surgimento de indústrias agro alimentares, têxteis e metalúrgicas nas proximidades da área rural onde

${ }^{24}$ Woortmann 1997: 50. 
residiam os colonos do Vale irá modificar profundamente esse panorama, com a entrada em massa dos colonos/as na condição de operários/as nessas indústrias, transformando-os em colonos/as operários/as, fenômeno que se observa, como já ocorrendo desde a terceira geração de imigrantes, como fica evidenciado no caso da trajetória familiar da Roseli Grossglags (agricultora), cujo pai trabalhava na Karsten e hoje é aposentado, tendo seu avô e bisavô que veio como imigrante para a região, trabalhado somente na lavoura.

Hoje na propriedade de Roseli Grossglags (agricultora), o trabalho na lavoura está voltado somente para o autoconsumo, como um complemento da renda familiar, que é totalizada pela aposentadoria do marido, da sogra, seu trabalho na Karsten, seu trabalho como diarista duas vezes por semana e pela venda do gado de corte. Ela possui um filho e uma filha. A filha trabalha na indústria e juntamente com um neto vive com ela e o filho mora numa casa alugada ao lado da propriedade familiar e trabalha como metalúrgico em uma indústria situada próxima à propriedade. Seu marido que está aposentado dedica mais tempo agora à agricultura do que quando trabalhava na Karsten.

De acordo com ela, hoje na região, o gado leiteiro está se acabando e sendo substituído pelo gado de corte. Segundo ela, há vinte anos atrás é que começou a se deixar de ter gado leiteiro. Quando ela chegou para morar juntamente com os sogros, em 1969, na propriedade do marido, depois do seu casamento, eles vendiam leite, aí eles foram engordando e matando. Em seguida seu sogro adoeceu e daí ele não podia mais trabalhar na roça como sempre fizera e a sogra também. (Observa-se que está também ocorrendo o envelhecimento da população na área rural) Depois gradativamente, as vacas foram envelhecendo. Daí como seu marido trabalhava na Karsten à noite, no terceiro turno, das dez da noite às cinco da manhã, parte da manhã ele dormia até uma e meia da tarde e no período da tarde, ela e o marido trabalhavam na roça.

Sim, sim, à tarde távamos nós dois na roça. De manhã eu tava sozinha na roça e a tarde era nós dois na roça. Plantava milho, aipim, batata... meu, plantava até mais do que hoje por que hoje já tem mais facilidade de comprar bastante coisa. $\mathrm{E}$ assim a gente foi diminuindo as vacas leiteiras e a gente viu que dava menos serviço o gado de corte e também...

Observa-se que com a entrada dos colonos como assalariados nas indústrias, levando ao trabalho em tempo parcial na propriedade agrícola, inviabiliza-se a criação das vacas leiteiras que exigem muito trabalho e dedicação, enquando o gado de corte é criado solto no pasto. Segundo ela esse não foi um fenômeno isolado, o gado leiteiro vem desaparecendo das propriedades rurais da região e sendo substituído pelo gado de corte, que não exige tanto trabalho e assim como a produção na sua propriedade, a maioria dos colonos também produz para consumo próprio: 
Uns vinte anos atrás, por que aqui na... na região era todo mundo que tinha gado leiteiro. E hoje em dia ... são poucos... poucos que tem ... muitos ainda tem gado, mas só uma, duas ou três cabecinhas assim de corte pra consumo próprio, bem dizer... e o resto é tudo ... deixa assim solto no pasto, só pra consumo próprio. Mas gado leiteiro mesmo, só pouco ... cada vez menos, muito pouco, muito pouco.

Esse fenômeno foi também observado entre os outros colonos/as entrevistados. Este problema está trazendo também a questão do sucessor, já que os jovens estão cada vez mais voltados para um outro projeto de vida, de trabalho assalariado e/ou estudo, ainda que valorizem residir no local de moradia dos pais, próximo à propriedade familiar e mantenham um ethos camponês. Em conversa com alguns jovens e pais destes foi possível perceber que os jovens desejam permanecer ligado ao campo, porém em condições diversas, com melhores condições de trabalho e acesso às mídias, internet e celulares. Entretanto, segundo algumas agricultoras entrevistadas isto ocorre mais enquanto os pais estão vivos, pois quando morrem, o que seria o herdeiro preferencial - o ultimogênito - acaba por assumir a administração da propriedade familiar, ou um outro na impossibilidade dele.

\section{O KOCHÄSE NA VISÃO DOS PRODUTORES}

Podemos apontar várias dimensões presentes na fala de produtores e agricultores sobre o Kochkäse. Em primeiro lugar ele é visto como um alimento fácil de preparar, "coisa prática, fácil de fazer, que todos os agricultores poderiam fazer”, na visão de Hanna Lora Dahlke (53 anos, hoje cozinheira da Festa Pomerana) “ (...) "Não tinham máquinas, coisas...”. Sua fala se reporta ao contexto da vida do colono, que como pudemos perceber, sempre exigiu muito trabalho e economia do grupo familiar doméstico, principalmente em se tratando do "colono fraco". Nesse contexto o modo de fazer o Kochkäse, dado a sua simplicidade não exigia muita trabalho, mas fornecia um importante complemento na alimentação, diversificando a comida, o que explica a sua presença no cotidiano do colono. De acordo com Elisa Gebhardt "Não... faziam para a família ter outro tipo de comida em cima da mesa. A vida dos meus pais era mais difícil que a minha, então é uma vida bem dura, é, cruel...".

O registro do Kochkäse como Patrimônio Cultural Imaterial é visto pela maioria dos produtores e agricultores como uma coisa positiva, importante para a comunidade, visto tratar-se de uma tradição de seus antepassados valorada por todos:

NÍVIA: E se o kochkäse for registrado o que vai significar pra vocês?

HANNA: Eu acho que já vai ser uma grande conquista porque é uma coisa nossa que veio com nossos antepassados e está sendo proibido por mesquinharia, 
perseguição. Para nós agricultores e pequenos que ainda planta alguma coisa, produtores de leite. Desde que eu me conheço de gente eu conheço o kochkäse nas festas. (Quais festas?) Festas de casamento, festa de aniversário, de rei rainha eu diria assim é um prato tradicional dos nossos antepassados. (Hanna Lora Dahlke, 53 anos, cozinheira da Festa Pomerana)

Quanto à visão que os colonos têm da proibição feita pela ANVISA da comercialização do Kochkäse, isto aparece como sendo fruto de falta de interesse por parte de políticos para com a manutenção da tradição. Sugerese também o interesse de lobbys de grupos poderosos, como exemplificado nas falas abaixo:

LORENZ (agricultor): Tudo integrado na natureza. Hoje, aqui na nossa região pelo menos, tem sido muito grande, a Cidasc hoje ela condena muitos tipos de criação, se ela viesse aqui no estilo de criação que nós temos é capaz de ter muita coisa para acabar com a minha criação aqui que diz que não pode. Que não pode por quê? Porque o grande, a agroindústria, não serve pra ela. Então é fora do estilo da agroindústria. Nós temos o cúmulo de em Santa Catarina em cada região tem um técnico pago pelas agroindústrias para vistoriar quantas galinhas eu tenho aqui. Ele vem aqui perguntar, faz uma vistoria para ver quantas galinhas, como é que eu crio tudo, e esse relatório vai tudo para a grande agroindústria. Agora, recentemente a Cidasc começou a pegar no pé com um tipo de agricultores que tratavam lavagem para o porco. Antigamente sempre era criado na lavagem. E não querem que trate. Claro, isso não vende milho, não vende ração, não vende antibiótico, não vende nada disso. Então vai na contramão do grande empresário da agroindústria. Então isso é até uma pressão muito grande. E infelizmente, a parte governamental hoje trabalha especificamente nessa área, fortalecer o grande e acabar com o pequeno. Então nós temos que mudar isso aí.

Além do Kochkäse eles reclamam também da proibição de comercialização de outros produtos provenientes da agricultura familiar na região. Esse é o caso do frango caipira e do ovo de galinha que também não pode mais ser vendido, tendo sido também proibido pela Vigilância Sanitária. Aparecida e Curt Tesseman são hoje produtores de Kochkäse produzindo um total de 250 quilos por semana que comercializam na feira ou com particulares que os procuram, já que por não terem uma situação legal, ficam impedidos de deixarem em mercados e padarias. Eles já não produzem o leite, pois já não vivem como colonos, segundo ele falou, significando com isso que não realizam atividades ligadas à agricultura familiar. Eles pegam o queijinho branco (Kremmerkäse) dos colonos, que constitui a matéria prima para a confecção do Kochkäse, pelo qual eles pagam de $\mathrm{R} \$ 500$ a $\mathrm{R} \$ 600$ reais por mês, o que segundo eles permite o sustento dos colonos. Com esse queijinho eles produzem um total de 250 quilos de Kochkäse por semana que 
comercializam. Eles questionam as proibições que estão incidindo sobre os produtos derivados da criação e agricultura dos colonos, argumentando a dificuldade para eles em subsistirem como agricultores e manterem o gado e a produção do leite. Além do queijinho branco (Kremmerkäse) e Kochkäse, essa proibição se estende à galinha caipira, aos ovos de galinha caipira, às conservas produzidas na pequena propriedade familiar, à manteiga e a nata caseiras.

APARECIDA (agricultora): Aí os filhos diziam assim pra nós, Meu Deus, graças à Deus que vocês apareceram na nossa vida pra comprar o queijinho (branco) porque se não a gente não ia ter o que fazer... daí agora... daí ontem a gente falou que a gente vai poder pegar tipo em fevereiro... porque agora para tudo e nós não temos mais espaço... Vão ter que jogar o leite fora, vão ter que jogar o queijinho fora... complicado.

Segundo os produtores e agricultores a Sopa preta ou Schwartsauer também foi proibida de ser comercializada, por conter o sangue dos animais. Por conta disso, ela deixou de ser feita, como era tradicionalmente, nas festas da igreja. Essas festas têm a ver com o dia dos santos padroeiros das Igrejas das comunidades. De acordo com a maioria dos agricultores o Kochkäse, o Kemmerkrase, Schwartsauer, as conservas, bem como os produtos tradicionais derivados da agricultura dos colonos, devem ser preservados, primeiro por se constituírem em uma tradição da região de colonização apreciada pelos colonos, de outro pelo fato de se constituir em produtos que são responsáveis pelo orçamento familiar.

LORENZ (agricultor): Isso é uma das tradições que o pessoal tem também, de fazer a cabidela. Aqui na nossa região também, nas festas de igreja, não tem uma festa de igreja que não tenha cabidela. Sábados à noite a cabidela é tradicional. Isso a gente está tendo também um sério problema porque eles dizem que não pode fazer sopa de sangue. Sopa de sangue é cultura, é a nossa tradição. Então isso não foi feita há dez anos atrás. Não. Isso vem de cem anos atrás ou mais. Cem anos é coisa que a gente sabe através dos avós, pessoas que falam, desde de criança que a gente já tem consumo. Então é costume que a gente tem. $\mathrm{Na}$ comunidade a data da inauguração é festejada, então cada comunidade, cada igreja evangélica, católica, tem as datas de festa. Então nessas datas de festa, sábado à noite, é feita a cabidela.

Existe ainda um grande questionamento por parte dos agricultores e das agricultoras sobre o fundamento da proibição do Kochkäse e sua exigência de pasteurização. $\mathrm{O}$ argumento utilizado por eles leva em conta o tempo de existência do seu consumo na região e o fato de nunca ter se constatado qualquer problema de saúde por quem o consome. Somente uma das agri- 
cultoras que tem uma agroindústria do Kochkäse legalizada e pasteuriza o leite, me falou que achava que a pasteurização livrava o leite de bactérias e que ela preferia o seu paladar. Os demais colonos além de questionarem o argumento da contaminação do leite, consideram que a pasteurização altera o paladar e afirmam que seus clientes também não apreciam.

ELISA (agricultora): Bem pouco, como já disse a vigilância sanitária quer proibir tudo? Então eles acham que da bacia da madeira vem os fungos, vê então, os antigos estariam tudo morto (risos), sempre digo que essas bacias que mostrei lá de madeira essas eram lavadas e escaldadas e botadas no sol para secar, não é como eles acham que é feito, é feito assim neste ponto os antigos eram mais caprichados que nós hoje em dia na realidade, lavo tudo e boto para secar mais, esse negócio de eles achar que os fungos vêm de lá...

LORENZ (agricultor): Não é viável. Aí tem aquela questão, se isso tudo matasse, nós nem estávamos aqui para contar a história.

LEDY (agricultora): É verdade. Ia estar tudo morto.

Para Alberto Lorenz, as proibições trazem além de tudo prejuízo no que diz respeito à presença dos jovens na área rural. De fato os jovens vêm participando da produção do Kochkäse e em alguns casos são parceiros dos pais nas pequenas agro industrías voltadas para os produtos tradicionais, tendo até notas fiscais próprias. Esse aspecto é importante pois está contribuindo para fixar o jovem na área rural, já que muitos estão migrando para a cidade como assalariados, ainda que uma maioria permaneça morando com a família e trabalhando na propriedade de maneira parcial. As reclamações como se estendem à ausência de uma política mais efetiva voltada para os agricultores, em especial para os jovens.

LORENZ (agricultor): Então não tem nada para a juventude rural, promover encontros entre eles, fazer uma transferência de experiências e isso não existe, então isso falta. Isso são ações que tem que voltar o mais rápido possível pra gente, porque nós não vamos conseguir viver simplesmente pro jovem assim vai pro campo que lá é bom. Não. Isso não vai. Aqui no nosso município de Indaial a gente, de todos os agricultores que nós temos ainda, não tem dez por cento de jovens. É preocupante.

Aparecida e seu marido consideram ainda os aspectos benéficos do Kochkäse para a saúde, pelo fato do queijo não possuir gordura, já que ele é feito com o leite desnatado.

As proibições realizadas pela ANVISA estão ocasionando segundo os produtores o desaparecimento da bacia leiteira, já que os colonos ficam impossibilitados de manterem o gado e sua produção, por isso vendem e passam a plantar pinus e eucalipto. Observamos uma grande quantidade 
de plantações deste tipo na região e inclusive o deslizamento de terras nas áreas plantadas, por ocasião de chuvas e geadas. Parece estar se criando ou acentuando com isso um problema ambiental. Segundo o ex colono Curt Tesseman, a região que já foi uma das maiores produtoras de leite está deixando de ser. De fato a região do Vale do Itajaí, tinha uma produção importante de leite que vem diminuindo desde a saída dos colonos para o trabalho na indústria, na medida em que como colonos ou colonas operários fica difícil manter a produção leiteira, já que este é um dos trabalhos que exige mais na propriedade familiar. Com as restrições à venda dos produtos tradicionais $\mathrm{e}$ do Kochkäse essa situação tende a se complicar.

Para aquelas que não comercializam mas produzem para a família, o Kochkäse é visto como um complemento da alimentação, que além de diversificar a comida, permite fazer economia na renda familiar. Elisa Gebhardt, viúva e agricultora, que realiza todo a cadeia produtiva do modo de fazer o Kochkäse, ordenhando ela mesma a vaca, considera esses aspectos:

ELISA (agricultura): É, na renda da família porque aí eles não precisam comprar o queijo prato ou mussarela, acho que é caro, já vai dez litros de leite, a gente paga 15,16 reais no queijo, quem pega o queijo kochkäse a gente tem pra renda. Pra nós, pra mim, eu ganho só uma pensão do meu marido então vai fazer falta este 15 reais, também gosto muito de comer este queijo. Não gosto dos feitos em fábrica. (Porque?) Porque transmite muito colesterol, muito rápido, primeiro eles usam coalhado para processar então é rapidamente processado, vai mais um produto para conservar, tudo isto tem química.

Para ela assim como a maioria dos colonos e colonas entrevistados, o fato de ser considerado um produto "natural" ou artesanal, não industrial, livre de produtos químicos, é um fator importante para se preferir o seu consumo ao do produto industrializado, que não se sabe o que ele contém.

Assim como as maneiras de fazer, as maneiras de comer o Kochkäse são muito variadas, como mostram as falas a seguir de produtores e agricultores:

INGRID (agricultora): Pode cortar e comer ele assim, colocar um pouquinho de sal em cima e comer assim. Pode pegar ele, esmagar com o garfo e colocar umas colheres de nata junto. Mistura que ele fica muito gostoso junto com melado. É, mas colocando o melado depois em cima do queijo. Entendes? Ele fica muito gostoso com geleia, mus, qualquer coisa. Esmaga ele e coloca a nata, aí mistura com um pouquinho de sal de novo e pode comer. Era muito comido, muito, muito, muito.

CURT (agricultor): É eu, cada um tem um gosto, eu gosto de comer pão com melado e sardinha. Tu já viu uma coisa dessa? Sardinha, mas aquela... não essa sardinha pequena, aquela sardinha em lata grande em sal. 
A partir da discussão que vem sendo realizada através da análise do conteúdo da fala dos produtores e agricultores é possível identificar a situação a que estão submetidos os colonos do Vale do Itajaí, em relação às restrições que vem sendo feitas pela ANVISA. Estas restrições passam pela exigência da legislação dos serviços de inspeção sanitária, que está obrigando os agricultores a incorporarem processos, técnicas, equipamentos e insumos desenvolvidos para a produção industrial, que são inadequados para a realidade cultural e econômica dos agricultores. Essas transformações estão gerando conflitos e contradições para os agricultores, que vêm como saída para a situação de crise da agricultura que estão vivendo, a venda de seus produtos tradicionais, a fim de fazer face à essa situação. Além de inviabilizar a venda desses produtos, em especial do Kochkäse, essas exigências acabam por colocá-los na ilegalidade, pois necessitam desse comércio para sobreviverem. Se a saída está na venda dos produtos tradicionais, as exigências acabam inviabilizando essa possibilidade, uma vez que como no caso do Kochkäse, com a exigência de pasteurização do leite, ele deixa de ser um produto tradicional artesanal, passando a não ser mais reconhecido por parte dos consumidores como tal. Sendo assim, o produto colonial tradicional portador de uma identidade de pertencimento a uma dada cultura e tradição valorada pelos agricultores e agricultoras passa a não ser mais reconhecido como tal, inviabilizando-se o seu comércio ao longo do tempo. Trata-se da imposição dos valores do mundo industrial sobre os do mundo doméstico - neste caso os produtos coloniais, passam a estarem submetidos a uma descaracterização, fazendo com que aos poucos desapareçam essas tradições, ainda que exista na fala dos produtores e agricultores uma resistência a essa descaracterização.

Ao longo da discussão que vem sendo feita pudemos observar que no trabalho na propriedade familiar, o homem detém o saber da agricultura enquanto a mulher detém o saber que lhes permite transformar os produtos da agricultura de alimento (natureza) em comida (cultura), através de um saber-fazer, passado de mãe a filha (ou a nora), a cada geração. Podemos pensar a existência desse saber como um conhecimento tradicional, que informa e organiza a agricultura e a produção de alimentos na propriedade familiar. A relação com a terra, o manejo dos animais e a produção dos alimentos, indicam que há no conhecimento tradicional das práticas adotadas pelos agricultores, um sistema onde as várias dimensões da vida e do trabalho estão articuladas. Nesse sistema, há dependência entre insumos e matéria-prima, estando as etapas de produção integradas. Sendo assim o Kochkäse enquanto parte do sistema alimentar que se desenvolve acoplado ao sistema agrícola na propriedade familiar, é ele mesmo um conhecimento tradicional - um saber-fazer. Esse saber-fazer se encontra vinculado a um modo de vida, onde a terra, a família, o trabalho e a comida são categorias nucleantes que se encontram interconetadas, definindo a maneira de ser e a identidade dos colonos. 
Esse conhecimento pode ser considerado $\operatorname{como}^{25} \mathrm{um}$ conhecimento diferente do tipo formal e autorizado, sendo transmissível em contextos de sua aplicação prática. Ao contrário do conhecimento formal, esse conhecimento está baseado em um sentimento, consistindo em habilidades, sensibilidades e orientações desenvolvidas através de longa experiência de condução da própria vida num ambiente particular. Uma das suas características principais é a relação que ele mantém com um habitat e um território, que nesse caso se constitui como um território de parentesco.

Esse modo de vida, de trabalho, de cuidado com os animais e com a terra permite ver que a modernização da agricultura na região estudada não foi muito intensa, as culturas agrícolas e alimentares e as relações locais não foram totalmente extintas, de modo que estratégias para o desenvolvimento rural tornam-se possíveis nesse caso, sugerindo a importância do reconhecimento, valorização e legitimação de práticas e modos de produção já existentes, de maneira diferente daqueles casos onde estas relações já se erodiram, como em alguns países da Europa, onde se torna necessário um movimento de reconexão dessas relações, caso se pretenda pensar na retomada desses conhecimentos tendo em vista o desenvolvimento rural. ${ }^{26}$ Podemos pensar ser este o caso da agricultura familiar que vem sendo desenvolvida pelos colonos no Vale do Itajaí. No que se refere à produção de alimentos, essas características apontam para a importância da valorização de origem dos alimentos' perspectiva que emerge vinculada a contextos em que conhecimentos locais estão conservados. ${ }^{27}$

A relação entre agricultura, produção de alimentos e práticas e conhecimentos tradicionais pode ser ainda analisada tomando-se o caso do Sistema Agrícola Tradicional do Rio Negro, no estado do Amazonas, região amazônica, registrado em 2010, como patrimônio cultural imaterial brasileiro pelo Instituto de Patrimônio Histórico e Artístico Nacional (IPHAN). ${ }^{28} \mathrm{O}$ registro deste bem imaterial, ancorado no cultivo da mandioca brava (Manihot esculenta), relaciona-se aos saberes de 22 povos indígenas localizados ao longo do Rio Negro. Neste caso, o que é particularmente interessante aprender é que

[a] solicitação de registro se refere à forma particular, e tradicional, de praticar a agricultura desenvolvida na região do Rio Negro. É entendida aqui como um conjunto de campo de expressões de saberes diferenciados que tratam do manejo do espaço, do manejo das plantas cultivadas, da cultura material associada e das

\footnotetext{
${ }^{25}$ Ingold (apud Prado) 2000: 25.

${ }^{26}$ Fontes (apud Cruz \& Menasche) 2012: 14.

${ }^{27}$ Fontes (apud Cruz \& Menasche) 2012: 14.

${ }^{28}$ Para maiores informações sobre o Sistema Agrícola Tradicional do Rio Negro acessar $<$ http://www.iphan.gov.br/bcrE/pages/indexE.jsf\#>.
} 
formas de alimentar-se decorrentes. A expressão sistema utilizada no título [do dossiê, documento para a solicitação de registro], evidencia a interdependência desses domínios de formas de fazer. Trata-se de registrar uma diversidade de processos que envolvem várias escalas ecológicas, biológicas, socioculturais e temporais, que atravessam domínios da vida material, social e econômica, que têm funções simbólicas e produtivas, que repousa sobre ecossistemas, plantas, conceitos e saberes, normas sociais e que suprem necessidades biológicas. ${ }^{29}$

Ainda que se trate de um contexto diferente daquele encontrado no Vale do Itajaí, a perspectiva adotada na pesquisa se pautou por essa orientação, buscando integrar as diferentes dimensões contidas no objeto de estudo, numa abordagem em "termos de sistema agrícola focando mais sobre processos do que sobre produtos" [...] uma vez que "o 'imaterial' não consiste em objetos mas sim na virtualidade de objetos, sua concepção, seu plano, o saber sobre eles. Conservar virtualidades, ou seja, o imaterial, é conservar processos."”30 Com base nessa visão identificamos que o kochkäse faz parte de um sistema mais abrangente onde coexistem práticas tradicionais ligadas ao sistema de cultivo e ao sistema alimentar do grupo, que por sua vez se encontra ligado à identidade, sociabilidade e modo de vida do grupo. Outro ponto que pode ser identificado diz respeito à necessidade de identificar instrumentos legais para a proteção de sistemas tradicionais, que permitam ao mesmo tempo, a valorização e o reconhecimento do papel dos agricultores responsáveis por reproduzir conhecimentos e práticas que dão sentido a esse sistema. $\mathrm{O}$ reconhecimento, valorização e legitimação de formas tradicionais de conhecimento e de práticas e modos de produção já existentes dizem respeito também a estratégias para o desenvolvimento rural. Essas perspectivas, ainda que fundamentadas em diferentes contextos e abordagens teóricas, estão em harmonia quanto à necessidade e relevância de valorização e proteção de formas de conhecimento tradicional, especialmente no que diz respeito aos espaços rurais, evidenciando, assim, a centralidade da preservação desses conhecimentos e, em decorrência, dos produtos - como é o caso dos alimentos tradicionais gerados nos espaços rurais. ${ }^{31}$ A perspectiva da reconexão e a valorização de redes alternativas que reconectem o alimento com a sua origem e a natureza numa perspectiva do desenvolvimento local, tem sido realizado de várias maneiras, mas a perspectiva que se apresenta mais interessante é aquela voltada para a agricultura. Nessa perspectiva não somente o conhecimento e modo de fazer do Kochkäse, deve ser objeto de proteção, mas todo o conhecimento produzido por esse tipo de agricultura,

\footnotetext{
${ }^{29}$ Emperaire 2010: 9.

${ }^{30}$ Emperaire et al. (apud Cunha) 2008: 4.

${ }^{31}$ Fontes (apud Cruz e Menasche) 2012: 16.
} 
incluindo todos os alimentos tradicionais gerados nesse sistema. Com isto se estaria contribuindo também para a preservação da agrobiodiversidade, ou diversidade dos sistemas agrícolas e às espécies a ele associadas. ${ }^{32}$

O resultado do Inventário apontou a importância do Kochkäse para a identidade das famílias agricultoras, encontrando-se o seu saber e modo de fazer imbrincado em seu modo de vida, uma vez que o modelo da agricultura aqui desenvolvido guarda características daquelas trazidas das regiões de origem, onde o gado leiteiro e seus derivados, tais como a nata, a manteiga, a ricota, o queijo, possuem um papel fundamental no seu sistema alimentar. A região possuía até a década de 1950, uma bacia leiteira muito importante, que deu origem à criação de inúmeras queijarias na região. Com a fragmentação e o esgotamento da terra, já a partir da segunda geração e o surgimento de inúmeras indústrias nas proximidades da área rural, ocorre o ingresso em massa dos agricultores familiares, o que se de um lado permite uma saída para a situação dos colonos através do seu assalariamento, por outro, ao transformar o colono em colono-operário, leva a que estes passem a trabalhar na agricultura em período parcial. Isso faz com que paralelamente ao envelhecimento da população, ocorra a diminuição do tempo disponível para a agricultura, levando o trabalhador a trabalhar mais para a autossubsistência, e diminuir progressivamente a sua produção leiteira, que aos poucos foi perdendo sua expressão na região. Nesse contexto o Kochkäse além da sua importância para a identidade e o modo de vida dos agricultores tem se apresentado como a fonte mais importante de renda, permitindo ainda que se mantenha o gado leiteiro, que na visão dos agricultores já teria se acabado se não fosse pela produção e venda do Kochkäse.

\section{REFERÊNCIAS BIBLIOGRÁFICAS}

Bourdieu, P. (1989), O Poder Simbólico, DIFEL, Rio de Janeiro.

Cruz, F. da \& Menasche, R. (2012) Modos de vida, alimentos tradicionais e patrimônios culturais: uma reflexão a partir do queijo serrano. I Seminário sobre alimentos e manifestações culturais tradicionais. UFS - 21 a 23 de maio.

Dorigon, C. e Renk, A. (2015), Técnicas e métodos tradicionais de processamento de produtos coloniais: de "miudezas de colonos pobres" aos mercados de qualidade diferenciada. Captado em http://www.alasru.org/wp-content/uploads/2011/07/GT4-ClovisDorigon.pdf.

Emperaire, L. (2010), O sistema agricola tradicional do Rio Negro. Dossiê de Registros. Brasília.

Emperaire, L. Velthem. L. von, Oliveira, A. G. de (2008), Patrimônio cultural imaterial e sistema agricola: o manejo da diversidade agricola no médio Rio Negro (AM),

\footnotetext{
32 Santilli 2009: 94.
} 
comunicação apresentada à 26a Reunião Brasileira de antropologia, ABA, 0104/06, Porto Seguro (BA).

Fonseca, M. C. L. (2003), "Para além da pedra e cal: por uma concepção ampla de patrimônio cultural”, in R. Abreu e M. Chagas, (coord.), Memória e Patrimônio: ensaios contemporâneos, Editora DP\&A, Rio de Janeiro, 56-80.

Maciel, M. E. (1996), "Churrasco à gaúcha”, Horizontes Antropológicos: Comida, 4: 34-48.

Menasche, R. e Schmitz, L.C. (2007), "Agricultores de origem alemã, trabalho e vida: saberes e práticas em mudança em uma comunidade rural gaúcha”, in R. Menasche (coord.), A Agricultura familiar à mesa. Editora da UFRGS, Porto Alegre, 77-98.

Prado, R.M. (2012), “Viagem pelo conceito de populações tradicionais, com aspas” in C. A. Steil e I. C. de M. Carvalho (coord.), Cultura, percepção e ambiente: Diálogos com Tim Ingold, Editora Terceiro Nome, São Paulo.

Santilli, J. (2009), Agrobiodiversidade e direitos dos agricultores, Peirópolis, São Paulo.

Seyferth, G. (1999), "A Colonização Alemã no Brasil”, in B. Fausto (coord.). Fazer a América, Editora da Universidade de São Paulo, São Paulo, 273-313.

Seyferth, G. (1993), "Identidade camponesa e identidade étnica”, Anuário antropológico 91: 31-63.

Silva, M. C. G. da. (2007), "O Impacto da Imigração Europeia sobre a produção de Alimento e a Culinária do Médio Vale do Itajaí", in M. F. Lima Filho, J F. Beltrão, C. Eckert (coord.), Antropologia e Patrimônio Cultural: Diálogos e Desafios Contemporâneos, Editora Nova Letra, Blumenau. 101-131.

Woortmann, E. e Woortmann, K. (1997), O trabalho da terra: a lógica e a simbólica da lavoura camponesa. Editora Universidade de Brasília, Brasília.

Woortmann, E. (1995), Herdeiros, Parentes e compadres: colonos do Sul e sitiantes do Nordeste. Ed. Universidade de Brasília, Brasília; Hucitec, São Paulo. 